\title{
Thoughts and Suggestions for Practical Teaching of Accounting in General Colleges
}

\author{
Xiaolei Zhang \\ Shenyang Aerospace University College of Economics and Management 110136
}

Keywords: Fundamental accounting; Practical teaching; Inter-cut experiment; Group Simulation

\begin{abstract}
Accounting theory teaching in general colleges has always paid attention to practical teaching, which leads to the separation of theory and practice. The combination of theoretical teaching and practical teaching is the internal requirement to improve teaching quality of the accounting, which is also an inevitable choice to enhance students ' professional skills. Concerning a series of problems in accounting practical teaching, the author will give advancement measures and suggestions according to 15 -year accounting teaching experience.
\end{abstract}

\section{Introduction}

Accounting is one of the most important skills that students engaged in business management must have for employment. However, at present, these students do not have practical ability and lack experience, which has severely restricted the development of talents. In addition, after the expansion of enrollment in colleges, there are not enough practical teaching bases so the declining of teaching effect has become a bottleneck under the environment of serve competition. This paper will give advancement measures as well as strategic suggestions for the problems in accounting practical teaching in general colleges.

\section{Analyze on the Problems of Accounting Practical Teaching}

While carrying out accounting treatment for virtual enterprises in accounting simulation laboratory, main problems show in the following:

The Experiment in Accounting Simulation Laboratory Is Divorced From Class Theoretical Teaching. In order to realize real-time interaction between theoretical teaching and lab, we have to solve the problem that theoretical knowledge is too abstract and find out the shortages in the classroom teaching based on experiment. However, at present, accounting simulation experiment is arranged after the completion of all courses which cannot timely supplement and improve each other. Therefore, the experiment will not work perfectly and the efficiency of theoretical teaching will also decrease. Accounting practical teaching takes simulation as the focus which has different comparing to real business and a lot of labs only provide the opportunity to conduct accounting practice without real interaction. Students get to be familiar with the original evidence based on training teaching material and complete registering accounting books with the guidance of teachers. However, there are diverse practical certificates, while the routinization of business flow cannot be fully demonstrated. Practical teaching materials are almost the same which cannot help to create a complete simulated-azimuth data system. In addition, the environment of practical training lab is not advanced and both the software and the hardware constructions lag behind.

The Teaching Materials of Accounting Stimulation Training Is Not Proper. In practical training, a common problem is that we put too much emphasize on auditing, ignoring accounting control. Accounting simulated practice

Accounting treatment based on new accounting standards requires professional judgment. However, in current accounting simulated experiments, there is rare professional judgment.

We focus more on experiment courses of financial accounting, while ignoring management accounting, financial management and auditing experiment. Most of the experiment teaching materials are simple, which can cover financial management, management accounting, taxes and 
finance. However, comprehensive experiment materials covering multi levels and directions remain to be developed.

Lack of Lab Faculties. Schools and the growth model lead to the situation that accounting teachers cannot or do not have many opportunities to participate in real accounting operation. Therefore, they have poor practical abilities while their guidance as well as explanation is in shortage of truth and authority. In addition, most of them are keen to theoretical research and do not have passion and desire to cultivate practical ability.

The Construction for Professional Practical Teaching Is Not in Place. Because of the non lot sizing requirement of accounting, it is difficult for students to be directly enrolled or accepted as an intern by outside enterprises besides practical training bases or school-enterprise cooperation. To conclude, it should be beneficial to both schools and enterprises whiles students should also improve their practical training ability or enterprise will not pay a handsome bill to cultivate them.

The Internal Requirement of College Teaching Supervision and Accounting Practical Teaching Is Not Coordinate. Teaching supervision is to supervise each teaching sectors in the premise that the teaching plan and agenda have been formulated while students qualities are different from previous years. Teachers should properly adjust theoretical and practical teaching time according to teaching contents and schedule of progress which may cause conflicts. Therefore, while there are problems, teachers will feel antagonistic and may escalate into emotional battles.

Graduation Practice Changes into Finding a Job. Graduation practice is the final sector that students can apply their knowledge into reality. However, due to the fact that financial divisions cannot provide many opportunities, it is really difficult to arrange internship. While approaching graduation, schools will just let them find a job, which will lose the last chance to improve students' comprehensive quality and teaching quality.

The Position and Function of Teaching Reforms Are Less Important than Other Research Projects. Concerning the consideration of leaders, the teaching reform is not research projects so in terms of title appraisal, it is inferior to research projects. As a result, teachers are not willing to carry out reform and contribute time and efforts to it.

\section{Advancement Measures and Suggestions for Accounting Practical Teaching}

\section{Perfect the Accounting Practical Course System. School experiments}

Based on existing financial accounting manual simulation experiment, and accounting electric simulation experiment courses we should add additional budget accounting, assets assessment, audit, simulation experiment courses to exercise students while facing different enterprises. What's more, we should also add additional financial management, and management accounting simulation experiment course to cultivate students financial decision and cost management decision capacity; furthermore, accounting planning simulation experiment courses should also be added to cultivate students' planning ability in terms of issued stock, transnational business, and organizing groups.

Outside School Practice. We should increase perception practice of accounting and production, which should be three-dimensional. In terms of time, students should learn how to understand cognitive account, voucher, report in the second semester of freshman year along with practice and demonstration. In terms of contents, they can go to enterprises to further feel the perception practice to conduct books, vouchers, statements and position setting to experience real accounting process. However, the production practice should not be whistlestop and we have tot add different types on internship based on demonstration and ask students to carry out group discussion, invite enterprise managers to do report in terms of accounting management etc to leave a deeper impression on students. By the way, while making videos, we should avoid simple replaying for production but combine the production process together with auditing, financial management, financial decision and accounting system design.

Add Accounting Positions. We should adopt the method of inviting and getting out to train accounting technician. Concerning concrete steps, we can firstly recruit senior accounts with abundant experience or those retired accounting technicians to go to the labs and make the experiment more real. Meanwhile, schools should strengthen professional training of accounting 
professional teachers to improve their professional qualities and allow them to participate in the follow-up education. Moreover, we should encourage teachers to do part-time job in enterprises so as to have a better understanding of accounting practice. Those with abundant practical experience should be professional accounting technician to timely know the change of accounting practice, revise experiment time and procedures, reform and perfect teaching methods as well as contents to better service teaching.

Innovate the Stimulation Experiment Teaching Method. The following teaching methods can be adopted in accounting experiment

Demonstration Experiment Teaching. For example, teachers can take advantage of accounting experiment teaching software to show students how to prepare certificate, record, and report with video, images and audio as well as teaching so as to help them have a comprehensive understanding of auditing process.

Inter-cut experiment teaching method. In experiment teaching, we can inter-cut some TV shows to help better understand the key points and difficulties. Fore example, we can inter-cut videos with bill processing to help them learn the process and inter-cut the production process to help them understand the production process.

Simulation practice in groups. It aims to let them act as the staffs of suppliers, transport units, purchasing units, and accounting units to convey relative certificate such as receiving invoice etc. What's more, accountable officer should go to virtual enterprises' bank of deposit to do the settlement. Through this, students are able to operate which combine teaching with practice and can activate the teaching atmosphere and strengthen students' perceptual awareness.

Module simulation practice. Module simulation takes the theoretical chapter as the unit to carry out organization experiment based on teaching schedule. After one chapter, students will be able to have a direct understanding in practical internship so that they can deepen their understanding.

Phase simulation practice. After completing a professional accounting course, there will be one to two weeks for students to deal with the accounting process. It begins to simulate an enterprise, deal with original evidence, fill out accounting voucher, record, prepare report with almost same situation in terms of contents, process and environment.

Comprehensive simulation training. Comprehensive simulation practice should be carried out after completing all the courses and before employment, which aims to improve students ' comprehensive ability. It will create a complete series of original materials after design and processing, and it let students act as the enterprise accountants to deal with simulated operation in accordance with the norms of accounting practice. In addition, it also allows students to make decision-making for financial management and simulated operation. Comprehensive simulation practice includes the basics of accounting, intermediate accounting, cost accounting, financial management, audit etc and aims to achieve the training objectives and requirements. By the way, it is no longer repeated phase practice but a higher level of accounting simulation practice. Its focus should relate company with the external economic environment to fully demonstrate practical abilities. Comprehensive simulation practice and graduation practice can be carried out at the same time. To be concrete, they can be arranged around the first or second weeks of the second semester of senior year while from the third to six week, they will go to enterprises to do internship which can to some extent have better effect. Furthermore, we should start from the perspective of employment position and requirement of enterprises to pay more attention to practical training of different positions and fields. Every student should do internship in different positions based on rotation so as to strengthen the sense of position.

Strengthen the Construction of Accounting Practice Base. Judging from the condition of accounting experiment labs, the most advanced labs cannot provide a totally same work environment so internship outside schools are irreplaceable. In practice, students do not have enough time and are not granted with a training base for a long time. What's more, some enterprises cannot accept enough interns and lack funds. Therefore, some schools cancel the outside school internship, they just adopt stimulation experiment to make up for the demerits of students. To conclude, to strengthen the construction of accounting practice base is also an important sector of 
strengthening practical teaching. We can adopt the following three methods to build the practice base:

Cooperate with Social Enterprises to Build Practice Base. Schools can cooperate with business firms or accounting firms to build allies of production, school and research to provide service with mutual benefits so that students can practice with a plan and in turn.

Create a Practice Base on Our Own. Colleges with good conditions can create a stable practice base on their own and let students as well as teachers to do the daily management. So, they can analyze and enterprise condition based on knowledge, which will increase their passion.

The government and local finance should give direct benefits and recognition to encourage enterprises to participate in the activities of improving accounting teaching quality so as to consolidate and strengthen their practice base.

In order to fully play the intellectual advantage of college students as well as the radiation effect on industry caused by professional research and meanwhile improve the ability of accounts, we should modify Law of PRC on Certified Public Accountants of China to allow non-profit accounting firms establishment set by accounts with CPA and teachers with higher professional tiles to provide practice bases for students.

Strengthen Accounting Experiment Teaching Material Construction. Because of the continuous change of economy, the accounting criteria should be modified and perfected along with time. Therefore, we should modify and perfect the teaching materials especially in the current conditions that assessment as well as theory are emphasized while supervision and practice are ignored so as to continually perfect the practice teaching materials.

Pay Attention to both Teaching Reform Subject and Research Projects. Government offices, especially colleges should change their title appraisal condition to weigh teaching reform subject and research projects as the same so as to highlight the direction function of teaching reform in improving education quality.

Coordinate Teaching Inspection and Control to Check Accounting Experiment Teaching. These two teaching management systems should encourage to timely change the teaching time, schedule and contents based on the real condition as well as students' understanding so as to make interaction between teachers and students and help students solve problems in accounting experiment.

\section{References}

[1] Wang Benqiang, Wu Xufen, Wei Zhubao. Demerits of current Fundamental Accounting and new teaching material proposition [J]. Finance and Accounting Monthly, 2010.9.

[2] Miao Qijun. Reform and innovation of fundamental accounting [J]. Friends of Accounting, 2010.1.

[3] Hu Lingyan. Discuss on the teaching reform on Fundamental Accounting for higher vocational education [J]. China Township Enterprises Accounting, 2010.1.

[4] Chen Liming. Brief talk on the elementary course of fundamental accounting [J]. Occupation, 2010.2.

[5] Liu Xuanhong. Discuss on the teaching method of Fundamental Accounting [J]. Science \& technology Information, 2010.17.

[6] Sun Yaling. Practice and thoughts on the collaborative teaching mode of international service trade [U] Journal of Zhejiang Wanli University, 2ulu. 23(3): 97 1uu

[7] Ni Chuoyuan. Discuss on the application of inclusive education in international service trade [U] Economic \& Trade Update. 2u11(6): 267268. 